\title{
Hepatobiliary Mucinous Cystadenoma of the Liver: A Case Report of a One-Year-Old Girl
}

\begin{abstract}
Amir Mohamadain'1, Sami A Taha', Azza A Abdelssatir ${ }^{2}$ and Ahmed A Abdalla ${ }^{3 *}$

${ }^{1}$ Department of Surgery, Al Neelain University, Sudan ${ }^{2}$ Ministry of Health, Histopathology, Khartoum, Sudan ${ }^{3}$ Departments of Surgery, University of Gezira, Sudan *Corresponding author: Ahmed A Abdalla, Departments of Surgery, University of Gezira, Sudan; Email: hantoub22@hotmail.com
\end{abstract}

Received: April 03, 2017; Accepted: July 05, 2017; Published: July 31, 2017

\begin{abstract}
Hepatobiliary cystadenoma is a rare cystic tumor of the liver, they account for less than $5 \%$ of nonparasitic cysts of the liver. We are reporting her an oneyear-old Sudanese girl with hepatobiliary cystadenoma. Ultrasound (US) and Computerized Tomography (CT) are most important for tumor diagnosis, but differential diagnosis with other cystic tumors of the liver and parasitic infection is difficult preoperatively. Complete surgical liver resection or enucleation is the treatment of choice.
\end{abstract}

Keywords: Hepatobiliary cystadenoma; Cystadenocarcinoma; Hydatid cyst

\section{Introduction}

Primary hepatic tumors account for about 5\%-6\% of all intraabdominal tumours in children and represent between $0.5 \%$ and $2.0 \%$ of all pediatric neoplasms [1]. Hepatobiliary cystadenoma is a rare [2] cystic tumor of the liver, they account for less than $5 \%$ of nonparasitic cysts of the liver [3], affects females predominantly with age range from 40 to 60 years at the time of initial diagnosis [4].

All the cystadenomas were multilocular with benign cuboidal to columnar epithelium, and 44 (85\%) had densely cellular spindle cell ("ovarian-like") stromata [5]. It is mostly benign with potential for malignant transformation [6].

Recent developments in diagnostic radiology techniques might help in differentiating cystadenoma from cystadenocarcinoma [7]. Internal septation and polypoid protrusions on CT scan should increase concern for malignancy [8] and hence complete resection is necessary due to this malignant potential of cystadenoma [7].

The aim of this case report is to demonstrate its clinical presentation, preoperative evaluation, and treatment.

\section{Case Presentation}

A 12-month-old girl presented with right upper abdominal mass for 40 days, increasing in size gradually without constitutional symptoms. The examination revealed soft lax abdomen, not tender and the liver was approaching the umbilicus. Laboratory tests were normal except a slightly elevated SGOT $(40 \mathrm{u} / \mathrm{L})$ and CA 19-9 (79 u/ $\mathrm{ml})$. Ultrasound scan showed large well-defined, thin wall cyst with septation occupying most of the right lobe of the liver, measuring 9.5 x $5.5 \mathrm{~cm}$, with no calcifications, and the impression was a hydatidcyst. And serology was negative for hydatid disease.

Contrast CT scan showed large rounded thick wall cystic mass with septations occupying segment V \& V1 suggestive of hamartoma or hydatid cyst (Figure 1).

At laparotomy, a huge cyst was found at the inferior surface of the liver to the left side of the gall bladder, aspiration turned to be a yellowish fluid (Figure 2), complete excision was done with a rim of liver, hemostasis achieved with cauterization and under-running of the edges done (Figure 3).

Histopathology reported multi-lobulated cyst lined by cuboidal epithelium with focal mucin secreting cells, the cyst wall was fibrotic \& showed proliferation of bile ducts. No evidence of dysplasia or malignancy consistent with hepatobiliary cystadenoma. The lesion completely excised.

She passed though uneventful post-operative period and two weeks follow up ultrasound showed no collection.

\section{Discussion}

Hepatobiliary mucinous cystadenoma is a rare benign cyst that originates from the liver and it is considered premalignant, which may be lethal if left untreated [9], which affect females more than males $[2,5]$. The malignant equivalent is biliary cystadenocarcinoma [9].

The reported case presented with a bigpalpable mass and the CT scan demonstrated it as a large, multilocular and cystic in appearance, as described by Devaney K [5]. And biliary cystadenoma typically have a smooth tumor wall with septa inside the tumor resulting in a "cystsin-cyst" appearance [10], which is typically present in reported case. This finding (Figure 1B) assist in identify it from simple hepatic cysts, as well as infectious or hemorrhagic cysts. Simple cysts usually have well defined tissue/fluid interface on CT scan [10] additionally Choi, et al. [11] reported that finding of a septum and septal thickening is a significant predictors of cystadenoma versus simple hepatic cysts in their series patients.

Hydatid cyst was on the top of our differential diagnoses list for this case. Echinococcal cyst and liver abscesses occasionally can be hard to differentiate from cystadenoma as reported by Keven [10]. Echinococcal cysts have many imaging criteria like daughter cysts, debris within the cysts, border irregularity, irregular shape and calcification [12].

Biliary cyst neoplasm in multiloculated hepatic cyst can be excluded by fine needle aspiration (FNA) of intracystic fluid. Horsmans Y, et al. [13]. Reported that the determination of serum and cyst fluid CA 19-9 may be of help in distinguishing between hemorrhagic simple 

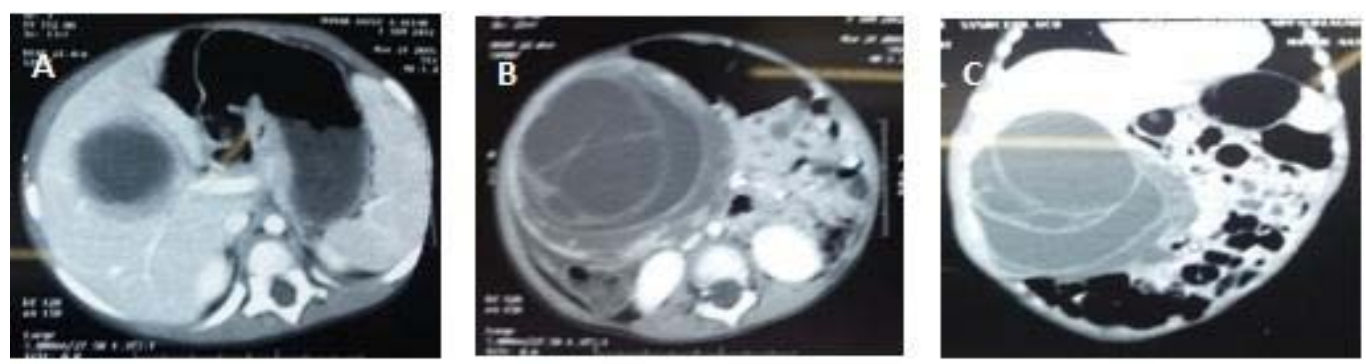

Figure 1: A,B,C:Abdominal enhanced computed tomography (CT), showing a large multilocular cystic mass in the liver cyst occupying segment $V$ and $V I$.
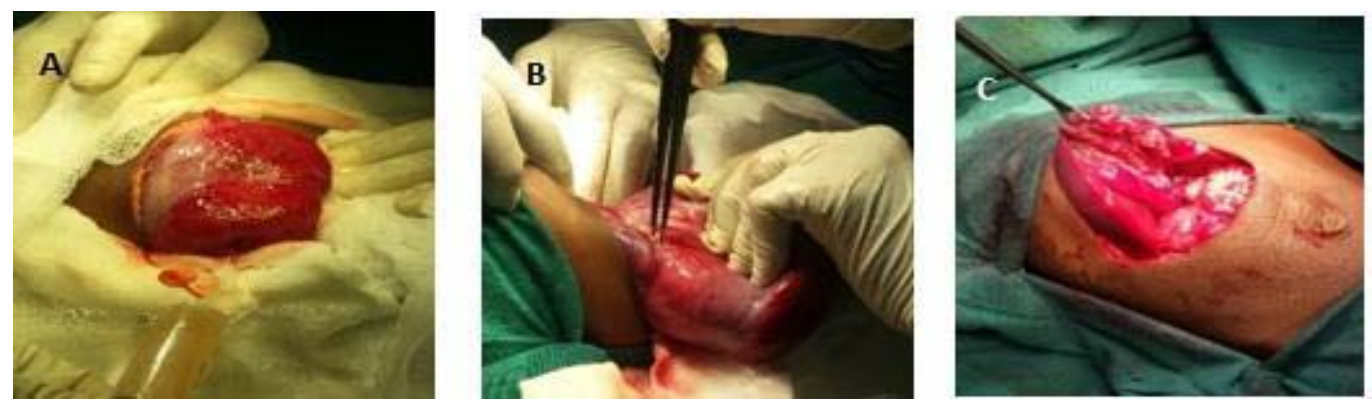

Figure 2: The cyst with the yellowish aspiration. B. Dissection and the resection plain. C. Cyst bed after resection and hemostasis.
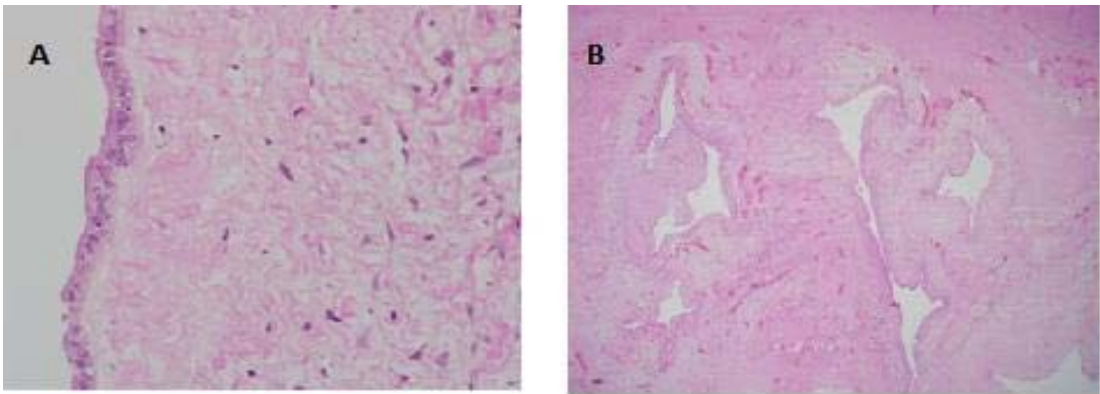

Figure 3: A. Single row of cuboidal lining epithelium. B. Multiple variably size cysts.

cyst and cystadenoma or cystadenocarcinoma and Pinto MM, et.al [14] reported that presence of atypical cells, mucinous material can be demonstrated in FNA and CEA assay gave a sensitivity of $100 \%$ and a specificity of $94 \%$, thus enhancing the sensitivity of FNA for the detection of malignancy in cystic liver lesions.

Biliary cystadenomas are multiloculated cysts with biliary-type cuboidal or nonciliated columnar epithelial lining, surrounded by a stroma that mimics ovarian stroma in about 85 to $90 \%$ of cases [5], this reported case is almost typical of what have been reported by others like Devaney K [5], but lacking the surrounded ovarian stroma.

Final decisions regarding indications and type of intervention should be discussed in a multi-disciplinary team (MDT), particularly in the case of cystic liver tumors; the most frequent mistake is the resection of a complicated biliary cyst incorrectly diagnosed as a cystadenoma [6].

Because of the malignant potential of the cystadenoma and the possibility of cystadenocarcinoma as a differential diagnosis, cyst resection is a treatment of choice $[6,9]$.
This case was treated by complete resection with rim of liver tissues, and this is one of the modalities of the treatment worldwide, Myung H Yoon, et al. [7] stated that excision of cystadenomas can be accomplished by either liver resection or enucleation. Regev A, et al. [15], in his review concluded that surgical resection is a safe and effective treatment for hepatobiliary cystadenoma, and accompanied with a low recurrence rate and long lasting relief of symptoms.

\section{Conclusion}

Biliary cystadenoma is a rare potentially malignant primary liver cyst. It should be considered when radiologic imaging reveals a multilocular cystic hepatic lesion. Treatment requires achievement of complete surgical resection, which will yields excellent results.

\section{References}

1. Liliana Chiorean, Xin-Wu Cui, Andrea Tannapfel, Doris Franke, Martin Stenzel, WojciechKosiak, et al. Benign liver tumors in pediatric patients Review with emphasis on imaging features. World J Gastroenterol. 2015; 28; 21: 8541-8561.

2. En-Liang Li, Shi-Dai Shi, Yong Huang, Lin-Quan Wu. Arrangements of Hepatobiliary Cystadenoma Complicated With Congenital Choledochal Cyst, 
A Case Report and Literature Review. Medicine. 2015; 94: e400.

3. Pillai SA, Velayutham V, Perumal S, Perumal SU, Lakshmanan A Ramaswamiet S, et al. Biliary Cystadenomas: A Case for Complete Resection. HPB Surgery. 2012; 2012: 6.

4. ALantinga M, Tom Gevers JG, Drenth JPH. Evaluation of hepatic cystic lesions. World J Gastroenterol. 2013; 19: 3543-3554.

5. Devaney K, Goodman ZD, Ishak KG. Hepatobiliary cystadenoma and cystadenocarcinoma. A light microscopic and immunohistochemical study of 70 patients. Am J SurgPathol. 1994; 18: 1078-1091.

6. DelPoggio P, Buonocore M. Cystic tumors of the liver: a practical approach. World J Gastroenterol. 2008; 14: 3616-3620.

7. Yoon MH, Yoon JW, Han BH. Mucinous cystadenoma of the liver with ovarian-like stroma: the need for complete resection. J Korean Surg Soc. 2011; 81: S51-54.

8. Mortelé KJ, Ros PR. Cystic focal liver lesions in the adult: differential CT and MR imaging features. Radiographics. 2001; 21: 895-910.

9. Yu FC, Chen JH, Yang KC, Wu CC, Chou YY. Hepatobiliary Cystadenoma: a Report of Two Cases. J Gastrointestin Liver Dis. 2008; 17: 203-206.
10. Soares KC, Arnaoutakis DJ, IhabKamel, Robert A, Adams RB, Bauer TW Pawlik TW et al. Cystic Neoplasms of the Liver: Biliary Cystadenoma and Cystadenocarcinoma. J Am Coll Surg. 2014; 218: 119-128.

11. Choi HK, Lee JK, Lee KH, Lee KT, Rhee JC, Kim KH, et al. Differential diagnosis for intrahepatic biliary cystadenoma and hepatic simple cyst: significance of cystic fluid analysis and radiologic findings. J Clin Gastroenterol. 2010; 44: 289-293.

12. Grisolia A, Troia G, Mariani G, E. Brunetti, C. Filice. A simple sonographic scoring system combined with routine serology is useful in differentiating parasitic from non-parasitic cysts of the liver. J Ultrasound. 2009; 12: 75-79.

13. Horsmans Y, Laka A, Gigot JF, Geubel AP. Serum and cystic fluid CA 19-9 determinations as a diagnostic help in liver cysts of uncertain nature. Liver. 1996; 16: 255-257.

14. Pinto MM, Kaye AD. Fine needle aspiration of cystic liver lesions. Cytologicexamination and carcinoembryonic antigen assay of cyst contents. ActaCytol. 1989; 33: 852-856.

15. Regev A, Reddy KR, Berho M, Sleeman D, Levi JU, Livingstone AS, et al Large cystic lesions of the liver in adults: a 15-year experience in a tertiary center. J Am Coll Surg. 2001; 193: 36-45.
Austin J Clin Case Rep - Volume 4 Issue 3 - 2017

ISSN : 2381-912X | www.austinpublishing group.com

Abdalla et al. () All rights are reserved
Citation: Mohamadain A, Taha SA, Abdelssatir AA and Abdalla AA. Hepatobiliary Mucinous Cystadenoma of the Liver: A Case Report of a One-Year-Old Girl. Austin J Clin Case Rep. 2017; 4(3): 1121. 